\title{
The Role of Socio-Cultural-Cognition in Disease Prevalence and Risky Behaviour among Children: A Conceptual Framework
}

Adele Munsami ${ }^{1 *}$, Carol Mitchell ${ }^{1}$, Lance Lachenicht ${ }^{1}$, Jane Dene Kvalsvig ${ }^{3}$, Eyrun Floerecke Kjetland ${ }^{2,3}$ and $^{\text {Myra Taylor }}{ }^{3}$

${ }^{1}$ School of Applied Human Sciences, University of KwaZulu-Natal, South Africa

2Department of Infectious Diseases Ullevaal, Oslo University Hospital, Norway

${ }^{3}$ Nelson R Mandela School of Medicine, University of KwaZulu-Natal, South Africa

\begin{abstract}
It is estimated that $93 \%$ of the global schistosomiasis prevalence is found in sub-Saharan Africa, with the highest prevalence and intensity rates occurring in children and adolescents. Schistosomiasis infection is associated with detrimental developmental effects. The current study presents a hierarchical conceptual framework for understanding the role of socio-cultural-cognitive factors that influence risk behaviour among children, especially young girls, living in this hyperendemic setting. This study sought to determine the impact of caregiver monitoring on adolescent girl's risk behaviours that may increase their risk of infection, especially with schistosomiasis, a neglected tropical disease that is pandemic in this region and has been associated with increased risk of HIV infection. This was a school-based, cluster, randomised, cross-sectional study conducted among 970 adolescent girls living in KwaZulu-Natal, South Africa. A questionnaire was administered by a trained research counsellor and urine samples were co microscopy. Microscopy results showed a moderate prevalence of schistosomiasis infection $(32.2 \%)$ among girls. Binary logistic regression revealed social (playing and swimming) and domestic (collecting water, doing laundry and washing blankets) water contact behaviours as significant predictors of infection. Caregiver monitoring was ineffective in reducing risk behaviours. The current study presents a conceptual model for understanding disease acquisition among children living in resource limited settings. The SCC model highlights the role of social and culturally rooted interactions that influence an adolescent girl's capacity to act; subsequently increasing their risk of schistosomiasis and HIV infection.
\end{abstract}

Keywords: Infectious disease; Adolescence; Risk behaviour; Schistosomiasis; South Africa

\section{Introduction}

\section{Background}

Despite unprecedented efforts to reduce the prevalence of disease in low resource, high burden, co-endemic settings, infectious diseases remain a public health challenge, especially in the developing world [1]. Within limited resourced contexts, the health of children and adolescents is further compromised by the presence of co-endemic parasitic diseases, including neglected tropical diseases (NTDs). These NTDs constitute a pandemic in such resource limited settings; and remain among the most commonly occurring chronic infections, affecting an estimated 2.7 billion people worldwide [2].

Schistosomiasis is a NTD that affects approximately 261 million people globally and leads to chronic ill-health and adverse outcomes (WHO, 2015). It is estimated that $93 \%$ of the global schistosomiasis prevalence is found in SSA, with the highest prevalence and intensity rates occurring in children and adolescents [2]. Schistosomiasis is acquired through direct contact with fresh water bodies that are contaminated with snail intermediate hosts [3]. Research conducted by Kvalsvig [4], amongst South African children, found that active children were more likely to become infected with schistosomiasis as a result of increased exposure to water. Consequently, water contact behaviour within this context, is a risk behaviour [5]. Risk behaviour, defined as potentially health damaging behaviour, is a globally acknowledged public health concern. During adolescence, children experience accelerated physical, psychological, social and cognitive changes along with a myriad of challenges [6]. Those growing up in the developing world must navigate through these experiences within a context of limited resources and pervasive adversity which may subsequently compromise their health and their development [6,7]. A meta-analysis of adolescent risk behaviour suggested a progressively earlier onset of risk taking behaviour, such as substance use, violence, sexual debut, increased risk of STI/HIV infection and pregnancy, among adolescents living in resource limited settings [8].

The effects of schistosomiasis infection have been associated with increased risk of HIV vulnerability and have been explored over the past decade [9-12]. Some findings suggests that the risk of horizontal transmission of HIV is increased in the presence of schistosomiasis which causes lesions or abrasions on the surface of the urogenital tract, that makes women and girls more susceptible to infection $[13,14]$. Findings from a study conducted by Brodish and Singh [12], found that women who developed female genital schistosomiasis (FGS) had increased numbers of HIV target cells and cell receptors which potentially increased their risk of HIV acquisition. The uncertainty regarding the role of the highly prevalent schistosomiasis parasite and the associated increased risk of HIV infection among adolescent girls living in SSA requires urgent attention.

\section{Theoretical framework}

A review summarising schistosomiasis research conducted in Africa, found that the prevalence of schistosomiasis was associated

*Corresponding author: Adele Munsami, School of Applied Human Sciences University of KwaZulu-Natal, 719 Umbilo Road, Congella, Durban, 4000, South Africa, Tel: 031260 4705; Fax: 031260 4566; E-mail: adeledelysia@gmail.com

Received October 24, 2016; Accepted November 02, 2016; Published November 09, 2016

Citation: Munsami A, Mitchell C, Lachenicht L, Kvalsvig JD, Kjetland EF, et al (2016) The Role of Socio-Cultural-Cognition in Disease Prevalence and Risky Behaviour among Children: A Conceptual Framework. J AIDS Clin Res 7: 631. doi 10.4172/2155-6113.1000631

Copyright: (C) 2016 Munsami A, et al. This is an open-access article distributed under the terms of the Creative Commons Attribution License, which permits unrestricted use, distribution, and reproduction in any medium, provided the original author and source are credited. 
with a variety of social factors, particularly the social context and social capital that arises in the home environment [15].

Sociocultural theory: Building on the key principles of Vygotsky's sociocultural theory, social capital, which consists of features of social organisation, such as high levels of interpersonal trust, mutual aid and reciprocity, serves as an intrapersonal resource for individuals. Social capital creates a context for interpersonal social communication of norms and values in a context of schistosomiasis, thereby facilitating actions that align with the cultural norms of the collective (social modelling), such as domestic water contact behaviours. This social phenomenon has the potential to account for group-level influences on individual health, such as caregiver modelling of domestic behaviours [16,17].

Social constructionism: Further to Vygotsky's sociocultural theory, social constructionism views ideas and knowledge as a social product that emerges in a context of communal construction between significant relations and children; arising in a social interchange between two or more persons in discourse around a subject, such as risk behaviours associated with disease [18]. Social capital, social communication and social modelling are regarded as a contextual variables passed on through generations. This recursive process influences cognitive processes that determine human action $[18,19]$. We present a multidirectional hierarchical socio-cultural-cognitive (SCC) model of disease that highlights the reciprocity between context, social interactions, behaviour and disease acquisition (Figure 1).

Socio-cultural-cognitive model: The proposed SCC model of disease acquisition consists of four fundamental stages of underlying socio-cultural and subsequent cognitive processes. These processes influence behaviour that may potentially be risky and, as a result, contribute toward disease acquisition. This conceptual model illustrates the important role of the broad social context that is unique to each culture. This context serves as a source of social capital for individuals operating within this context which directly influences the interpersonal level through social communication and social modelling.

Caregiver monitoring within a context of disease is particularly interesting, as it is regarded as an interpersonal activity that arises from the social capital that is available to children and adolescents in their immediate environment. The interaction that occurs during caregiver monitoring creates an opportunity for social communication of risk behaviours, particularly risk behaviours associated with schistosomiasis and HIV infection, as well as social modelling of culturally relevant behaviours. Social communication and modelling that arise during such caregiver interactions are influenced by intergenerational representation and involve the transmission of knowledge, especially culturally and historically rooted perceptions, beliefs and behavioural practices [20]. Therefore, adolescent knowledge regarding risk behaviour associate with schistosomiasis and/or HIV infection are dependent on the knowledge of caregivers that is passed on through each generation.

The outcome of caregiver monitoring at the interpersonal level manifest at an intrapersonal level, as this socio-cultural activity creates an opportunity for caregivers to shape individual cognition through social communication and modelling. This cognitive process subsequently influences the way individuals think, what information is recalled, how the information is interpreted and how the correct action is determined and performed. The resulting behaviour may increase an individual's risk of disease acquisition. The proposed SCC model of disease acquisition illustrates the reciprocity between social context and underlying cognitive processes that directly influence health and well-being, by highlighting a recurrent, multidirectional process that occurs within each stage of the model as well as between each level of disease acquisition. Socially communicated messages that arise from the sociocultural context, shape perceptions, communicate social norms and subsequently determine behaviour that may be risky within a certain context, resulting in adverse outcomes.

\section{Current Study}

Among low to middle income countries, South Africa is a wellknown example of a country with hyperendemic co-infection and co-morbidities such as schistosomiasis and other neglected tropical diseases $[21,22]$. In the light of studies that highlight that the presence of schistosomiasis affects school aged children, especially young girls

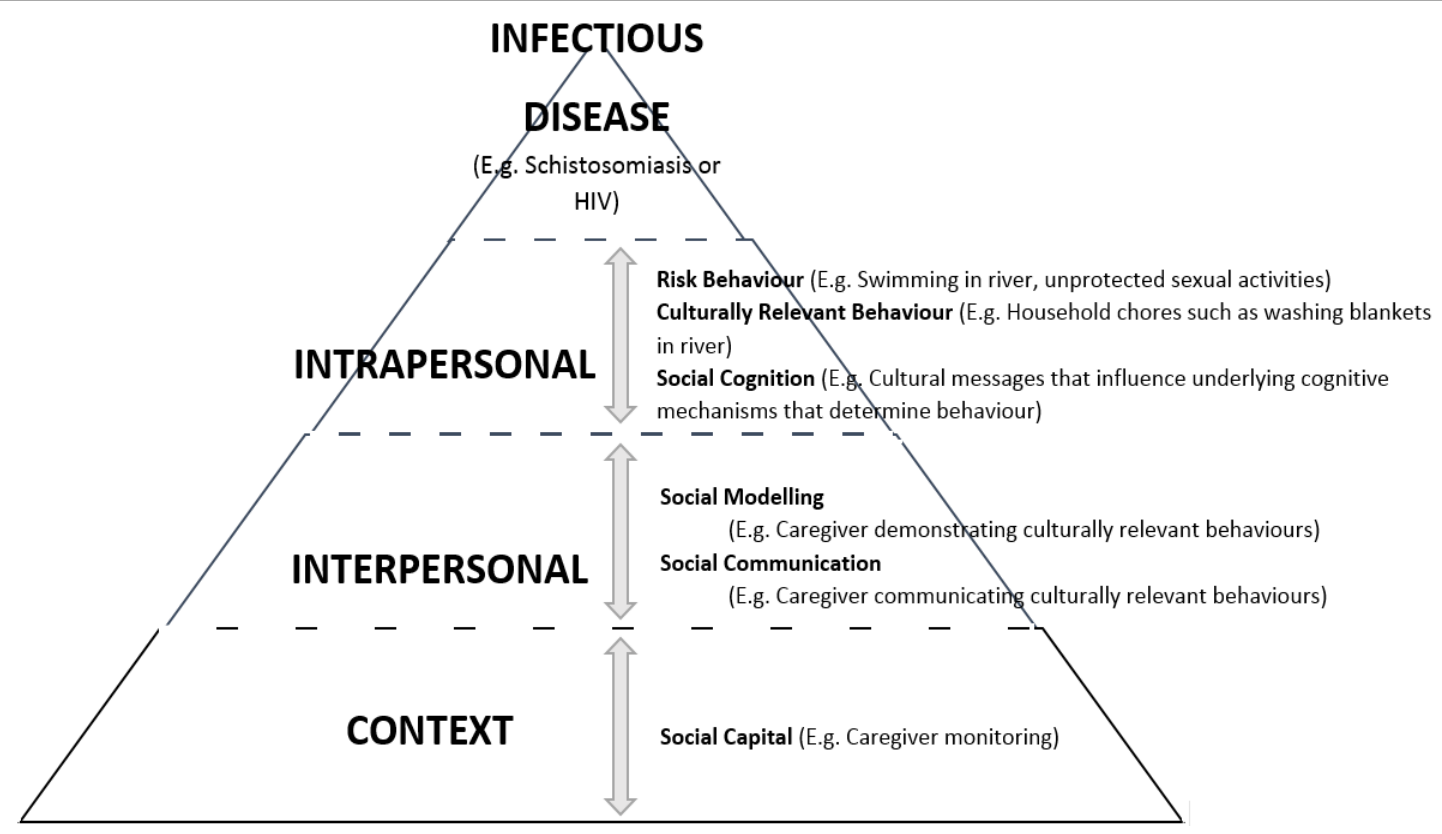

Figure 1: Hierarchial socio-cultural-cognitive model of disease acquisition (SSC model). 
[23], this study sought to understand risk behaviours engaged in by children and adolescents in a schistosomiasis endemic region, to explore the role caregiver monitoring on risk behaviour, from a sociocultural perspective and to determine whether this was associated with schistosomiasis infection, which may inadvertently increase risk of HIV infection, as suggested by Kjetland and Ndhlovu [10].

\section{Methods}

\section{Study design}

This study was nested within a school-based, cluster, randomised, cross-sectional study, conducted in 18 government schools between September 2009 and November 2010. The schools were located in a Schistosoma haematobium endemic area and a high HIV prevalence district (Ugu), on the south coast of KwaZulu-Natal, South Africa $[24,25]$. Introductory meetings were held at each school and study related information was provided to parents and children. Eligibility for recruitment and participation was as follows: attended a school located more than $10 \mathrm{~km}$ from the coast, but less than $300 \mathrm{~m}$ above sea level. Preteen adolescent girls at high risk of schistosomiasis who were between the ages of 10-12 were invited to participate [24]. Absenteeism during introductory visits, serious illness, caregiver refusal or incomplete study investigations, were considered exclusionary criteria.

\section{Study setting}

The population in the Ugu district is an estimated 733228 , almost exclusively isiZulu speaking people, with $84 \%$ of the population residing in resource limited settings [26]. Approximately $51 \%$ of the population are below the age of 20 years and $55 \%$ of the general population in this area are female [24]. HIV prevalence rates the in Ugu district have been reported to be as high as $30.1 \%$, making this area a high risk region for HIV infection [27].

\section{Ethical considerations}

The broader study was approved by the Biomedical Medical Research Ethics Administration, University of KwaZulu-Natal 2009, Reference BF029/07; by the Department of Health (DoH), Pietermaritzburg, 2009, Ref HRKM010-08; by the Norwegian ethics committee, Ref 469-07066a1.2007.535, 2007 and the Departments of Health (2008) and Education (2009) both provincially and in Ugu District. The Helsinki Declaration was followed. This sub-study was approved by the University of KwaZulu-Natal Humanities and Social Sciences Research Ethics Committee.

Prior to implementing the study, community leaders were approached and their approval obtained. Factual information about the study including participation, methods and procedures were explained to all participants in their preferred language, either English or isiZulu, by a trained female research assistant. Permission was obtained from the caregivers through written informed consent. Participants were also required to provide assent. Each girl was given a container and requested to provide a urine specimen in a numbered bottle to ensure anonymity. This collection was monitored.

\section{Data collection}

Questionnaire: Due to the contemporary nature of the study, it was necessary to develop a specialised instrument, guided by existing pre-tested psychometric tools that explored adolescent risk behaviour, whilst also incorporating schistosomiasis specific risk behaviours [28]. Questionnaire items were adapted from the Bonding Family Social Capital Scale and The Bonding Peer Social Capital Scale [29], the 10- item Likert Rosenberg's Self-esteem Scale (RSE) [30] and Bandura’s Self-Efficacy Scale [31]. Each scale yielded a Cronbach's alpha that ranged between 0.85-0.92 [32].

The questionnaire was translated from English into isiZulu, back translated and thereafter piloted at one school not included in this study. The questionnaire explored the home environment, water contact, risk behaviour, history of red urine, and history of genital symptoms. The current study considered the socio-behavioural components of the data. Risk behaviours were categorised into two groups. Firstly, general risk behaviours explored sexual risk behaviours, alcohol consumption and drug use. Secondly, schistosomiasis specific risk behaviours comprised of contact with water bodies, defined as a river, dam, lake, stream or pond; through seven culturally relevant water related activities (playing, swimming, washing, bathing, laundry, washing blankets, collecting water, fishing and crossing the river) [24]. Caregiver monitoring was defined as the presence of a caregiver during the day, at night, on weekdays and during the weekends. Caregivers were not approached for information.

Parasitology: Participants submitted three urine samples over three consecutive days between 10:00 and 14:00 [28]. Sample collection and microscopy are described in detail elsewhere [24]. The presence of at least one egg or ovum of a schistosoma species was regarded as positive for schistosomiasis infection.

\section{Data analysis}

Details on data management are reported by Hegertun et al. [24]. Cross tabulation tests were performed, using Statistical Package for Social Sciences (SPSS version 21), to identify significant relationships between schistosomiasis infection, risk behaviour, and caregiver monitoring. Due to the large number of association tests performed, a conservative alpha $(\mathrm{p}<0.001)$ was used to prevent family wise error in the contingency table analyses. Adjusted residual values were evaluated to understand the particular nature of any association [33]. Since adjusted residuals in contingency tables have a standard normal distribution, adjusted residuals that were greater than or equal to positive or negative 1.96 were considered to be significant contributors to the relationship and provided evidence against independence. Logistic regression was conducted to identify behavioural predictors of schistosomiasis infection, with a 95\% confidence interval (95\% CI) and alpha $(\mathrm{p}<0.05)$

\section{Results}

The median age of female participants was 11 years (range 10-12) and the median grade was 5 (range 1-7). In total, 32.2\% (312/970) children were infected with schistosomiasis. The main water source reported by participants was the stand pipe or communal tap $(71.2 \%$, 691/970) and the role of the main caregiver was reportedly fulfilled by a female figure $(87.9 \%, 853 / 970)$.

\section{Adolescent risky behaviours associated with schistosomiasis}

The findings from this study highlight social (swimming, playing) and domestic activities (washing blankets, doing laundry and collecting water) were significantly associated with schistosomiasis infection. Table 1 provides a summary of the behaviours associated with schistosomiasis infection. Fishing, sexual activity and substance use were excluded from further analyses due to low reporting frequency.

\section{Caregiver monitoring among adolescent girls}

Most participants reported being monitored by a caregiver at night 
(81.5\%, 791/970), however on the weekend only 48.7\% (472/970) were monitored and during the day only 38.0\% (369/970). Participants also reported daily rates of caregivers asking about school (75.5\%, 732/970), where the girls were going $(70.7 \%, 689 / 970)$ and with whom they were going $(73.9 \%, 717 / 970)$. For the purpose of this study, caregiver monitoring on weekends was explored due to the increased period of free time among children, which would require monitoring by caregivers. The prevalence of schistosomiasis was not associated with the frequency of caregiver monitoring on weekends $\left(\chi^{2}(3)=7.364\right.$ $\mathrm{p}=0.06)$. Table 2 summarises behaviours associated with caregiver monitoring. It is evident that only alcohol consumption and crossing the river were significantly associated with caregiver monitoring on weekends $(\mathrm{p}<0.0001)$.

\section{Predictors of schistosomiasis infection among adolescent girls}

Table 3 outlines the logistic regression analysis, conducted to identify risk behaviours that would potentially increase the chance of schistosomiasis infection amongst children. The model was adjusted for covariate factors, such as age, water source, and presence of a parent/caregiver, a mother present and a father present. The overall prediction success for the logistic regression models was $68 \%$. This suggests that there are other factors not included in the model that may influence the probability of infection. The odds from the adjusted model identify, broadly, two groups of behavioural predictors of infection, social (swimming and playing) and domestic (bathing, crossing the river, collecting water, doing laundry and washing blankets).

General risk behaviours, such as alcohol consumption were not a significant predictor of risk behaviour associated with schistosomiasis infection (adjusted odds ratio (aOR): 0.992; 95\% CI: 0.997-1.007; $\mathrm{p}=0.28$ ). Water contact behaviours that predicted schistosomiasis infection are as follows: playing in the river (aOR): $2.042 ; 95 \% \mathrm{CI}$ : 1.528-2.730; $\mathrm{p}<0.0001$ ), swimming in the river (aOR): 1.875 ; $95 \% \mathrm{CI}$ : $1.373-2.562 ; \mathrm{p}<0.0001$ ), washing blankets in the river $(\mathrm{aOR}): 1.815$; 95\% CI: 1.340-2.459; $\mathrm{p}<0.0001$ ), doing laundry (aOR): 1.783; 95\% CI: 1.313-2.299; $\mathrm{p}<0.0001$ ), collecting water (aOR): 1.683; 95\% CI: $1.242-$ 2.281; $\mathrm{p}=0.001$ ), crossing the river (aOR): $1.504 ; 95 \%$ CI: $1.118-2.022$; $\mathrm{p}=0.007)$ and bathing (aOR): 1.441; 95\% CI: 1.057-1.884; $\mathrm{p}=0.02)$. The

\begin{tabular}{|c|c|c|}
\hline Frequency Analysis & $n=970$ & $(\%)$ \\
\hline \multicolumn{3}{|c|}{ Schistosomiasis infection } \\
\hline Positive & 312 & 32.16 \\
\hline Negative & 658 & 67.83 \\
\hline \multicolumn{3}{|c|}{ Risky Behaviour } \\
\hline Illicit Drugs $\Omega_{Q}$ & 15 & 1.5 \\
\hline Alcohol $\Omega$ & 171 & 17.6 \\
\hline Swimming ${ }^{\ddagger}$ & 226 & 23.3 \\
\hline Playing ${ }^{\ddagger}$ & 306 & 31.6 \\
\hline Bathing $\neq$ & 317 & 32.7 \\
\hline Laundry $\ddagger$ & 380 & 39.2 \\
\hline Collecting Water $\ddagger$ & 256 & 25.8 \\
\hline Washing Blankets ${ }^{\ddagger}$ & 249 & 25.7 \\
\hline Crossing River $\ddagger$ & 250 & 25.8 \\
\hline Fishing ${ }^{\circ}$ & 13 & 1.3 \\
\hline Sexual Activity ${ }^{\Omega} \varphi$ & 3 & 0.3 \\
\hline
\end{tabular}

$\Omega$ General Risk Behaviour

‡ Schistosomiasis risk behaviour

- Excluded from further analysis due to low

reporting frequency

Table 1: Schistosomiasis infection and risky adolescent behaviour. results show that the odds of culturally relevant behaviours were not reduced in the presence of a caregiver.

\section{Discussion}

This paper presents a socio-cultural-cognitive (SCC) model of disease acquisition to further understand the role of culture, social communication and modelling of socially relevant behaviours in adolescent risk behaviour, in a limited resource setting. The findings from this study show that schistosomiasis is a problem amongst young girls living in South Africa. This study also demonstrated that caregiver monitoring would have been ineffective in preventing schistosomiasis, as domestic activities were the highest predictors of infection. Research conducted in the developed world suggests that the role of caregiver monitoring is associated with fewer risk behaviours among adolescents in later stages of development [34], whilst other studies have shown that caregiver monitoring can be considered as a buffer against risk behaviour [35-38]. Conversely, our findings showed that among children living in a rural, resource poor area in South Africa, caregiver monitoring did not reduce risk behaviour, in particular water contact behaviours.

Moreover, our findings highlight that households were predominantly headed by a female in this endemic area, where behaviours associated with domestic activities, such as doing laundry and washing blankets in the river were also commonly performed by children. In a rural setting where access to water remains a scarce resource, the use of open water sources such as rivers remain a key

\begin{tabular}{|c|c|c|c|c|c|c|}
\hline \multicolumn{5}{|c|}{ Chi Square } & \multirow{2}{*}{\multicolumn{2}{|c|}{$\begin{array}{l}\text { Residual Values } \\
\text { Risk Behaviour }\end{array}$}} \\
\hline & \multicolumn{3}{|c|}{$\begin{array}{c}\text { Caregiver } \\
\text { Monitoring }\end{array}$} & \multirow[b]{2}{*}{ Level } & & \\
\hline & Value & df & sig. & & $\begin{array}{c}\text { Yes } \\
\text { (engaged in } \\
\text { activity) }\end{array}$ & $\begin{array}{l}\text { No (did not } \\
\text { engage in } \\
\text { activity) }\end{array}$ \\
\hline \multirow{3}{*}{ Swimming } & \multirow{3}{*}{12.4} & \multirow{3}{*}{2} & \multirow{3}{*}{0.002} & Sometimes & -1.0 & 0.6 \\
\hline & & & & Most Days & -2.0 & 1.1 \\
\hline & & & & Everyday & 2.1 & -1.2 \\
\hline \multirow{3}{*}{ Playing } & \multirow{3}{*}{9.9} & \multirow{3}{*}{2} & \multirow{3}{*}{0.007} & Sometimes & 1.5 & -1.0 \\
\hline & & & & Most Days & -2.1 & 1.4 \\
\hline & & & & Everyday & 0.3 & -0.2 \\
\hline \multirow{3}{*}{$\begin{array}{l}\text { Washing } \\
\text { Blankets }\end{array}$} & \multirow{3}{*}{3.5} & \multirow{3}{*}{2} & \multirow{3}{*}{0.174} & Sometimes & 1.4 & -0.8 \\
\hline & & & & Most Days & -0.3 & 0.2 \\
\hline & & & & Everyday & -0.8 & 0.5 \\
\hline \multirow{3}{*}{$\begin{array}{l}\text { Doing } \\
\text { Laundry }\end{array}$} & \multirow{3}{*}{1.6} & \multirow{3}{*}{2} & \multirow{3}{*}{0.453} & Sometimes & 0.8 & -0.7 \\
\hline & & & & Most Days & -0.1 & 0.1 \\
\hline & & & & Everyday & -0.5 & 0.4 \\
\hline \multirow{3}{*}{$\begin{array}{l}\text { Collecting } \\
\text { Water }\end{array}$} & \multirow{3}{*}{9.2} & \multirow{3}{*}{2} & \multirow{3}{*}{1.10} & Sometimes & 2.0 & -1.2 \\
\hline & & & & Most Days & -1.6 & 1.0 \\
\hline & & & & Everyday & -0.3 & 0.2 \\
\hline \multirow{3}{*}{$\begin{array}{l}\text { Crossing the } \\
\text { river }^{a}\end{array}$} & \multirow{3}{*}{16.6} & \multirow{3}{*}{2} & \multirow{3}{*}{$<0.0001$} & Sometimes & $2.4^{b}$ & -1.6 \\
\hline & & & & Most Days & $-2.4^{b}$ & 1.6 \\
\hline & & & & Everyday & -0.1 & 0.0 \\
\hline \multirow{3}{*}{ Bathing } & \multirow{3}{*}{4.6} & \multirow{3}{*}{2} & \multirow{3}{*}{0.103} & Sometimes & 0.5 & -0.4 \\
\hline & & & & Most Days & -1.5 & 1.1 \\
\hline & & & & Everyday & 0.7 & 0.2 \\
\hline & & & & Sometimes & 1.5 & -0.5 \\
\hline $\begin{array}{c}\text { Alcohol } \\
\text { consumption }\end{array}$ & 85.4 & 6 & $<0.0001$ & Most Days & 1.3 & -0.6 \\
\hline & & & & Everyday & $-2.0^{b}$ & 0.8 \\
\hline
\end{tabular}

$\mathrm{df}=$ degrees of freedom; sig.=significance leve

a Significant associations $(p \leq 0.001)$

b Significant residual values $(\geq 1 \leq 1.96)$

Table 2: Caregiver monitoring and early adolescent risk behaviour. 
water source for essential activities that are culturally relevant for young females to participate in, often in the presence of a caregiver. Many generations of women living in rural areas have relied on access to rivers for their day-to-day activities, which has subsequently become a normative behaviour in these settings, despite having access to stand pipes or communal taps.

Importantly, this study highlights the role of cultural cognition arising from social constructionism on human action that increases their risk of acquiring diseases. The SCC model highlights the context and immediate environment as a source of knowledge for attitudes and beliefs that inform cognitive processes which, in turn, bring about culturally relevant behaviours. According to the SCC model, social capital, arising from caregiver monitoring by mothers, grandmothers, aunts and sisters, creates an opportunity for culturally relevant messages to be socially communicated and for culturally relevant behaviours to be modelled. Although these behaviours may be risky in a disease endemic setting, they are imitated and inherently adhered to by adolescent girls, thereby increasing their risk of disease acquisition. This study highlights that knowledge surrounding risk of infection are dependent on intergenerational knowledge transmission, suggesting that risk reduction counselling for schistosomiasis and HIV, should be targeted at both caregivers and children in this setting.

It is apparent that ordinary, everyday activities such as household chores, become risk behaviours in a schistosomiasis endemic region. This highlights the concealed risks faced by children in SSA. Adolescent girls who are infected with schistosomiasis may develop FGS and may be at an increased risk of HIV infection as they become sexually active and this may partly account for the high prevalence of HIV among girls between 12 and 15 years [39]. This study stresses the need for a contextualised understanding of disease as a platform to inform effective and targeted interventions, by linking disease acquisition to social communication, behaviour modelling and social cognitive processes that determine human action.

It is also disconcerting, that within a schistosomiasis endemic region nearly half of the children reported playing in the river. Moreover, a quarter reported of children reported that they frequently swam in the river, further highlighting the role of social communication and the modelling of culturally and historically rooted behaviours. To iterate, the current findings highlight the influence of culture specific, socially normative behaviours that are unique to each community and the subsequent effects of these practices, on risk perception, that are shaped by cultural identity, passed down from one generation to the next. This is especially relevant, when these behaviours are enacted by several referential individuals. This notion is supported by published reports which suggest that caregivers influence the way children view and understand their social environment, especially with regard to disease [20].

\section{Implications}

It is thus clear that the socio-cultural environment has a direct impact on the behaviour of children, especially risk behaviours that emerge during their earlier periods of development. Preventative strategies aimed at reducing the prevalence of schistosomiasis, other NTDs and infectious diseases in SSA must consider the socio-cultural and contextual norms. Future intervention strategies also require reevaluation and a shift toward strategies that incorporate social, cultural, cognitive and lifestyle factors, outlined in the SCC model; which are associated with disease acquisition. Moreover, these strategies should target caregivers and adolescents. For this to be achieved, validated and contextualised, socio-cultural-cognitive evaluation tools need to be developed in the field of NTDs, in order for preventative strategies to make a meaningful impact in reducing the prevalence of such infectious diseases in limited resource settings. The SCC model is a potential model that may account for these socio-cultural factors and requires further exploration in future infectious disease studies in this setting.

\section{Limitations}

Recall bias and self-report influence the accuracy of the data in this study. Secondly, Nagelkerke $\mathrm{R}^{2}$ values were less than 0.50 and the small decrease between the unadjusted and adjusted models suggest that there are a number of other factors, not included in this particular model, that account for the odds of infection. However, this is not uncommon in the field of biomedical research as the cause of disease is attributed to multiple factors. Further limitations included the absence of the caregiver to provide informed consent for participation, which may have resulted in those children who lack caregiver supervision not being included in the sample. Furthermore, this study focused on girls and their risk of female genital schistosomiasis, but young boys are also at risk of schistosomiasis, a debilitating disease [5]. Although the study included schistosomiasis, alcohol use and risky sexual behaviour, other adolescent risk behaviours such as road traffic behaviour were not included.

\section{Conclusion}

The current findings highlight the crucial role of unacknowledged socially, culturally and developmentally rooted behaviours that are determined by social cognition. These behaviours are associated with schistosomiasis infection that may influence the hyperendemicity of HIV in South Africa, especially among young women. Our study calls

\begin{tabular}{|c|c|c|c|c|c|c|}
\hline Risk Behaviour & $\begin{array}{l}\text { Schistosomiasis } \\
\text { positive }(\%)\end{array}$ & $\begin{array}{c}\text { Schistosomiasis } \\
\text { negative }(\%)\end{array}$ & $\begin{array}{l}\text { Unadjusted Model } \\
\text { OR }(95 \% \mathrm{Cl})\end{array}$ & p-value & $\begin{array}{c}\text { Adjusted Model OR } \\
(95 \% \mathrm{Cl})\end{array}$ & $p$-value \\
\hline Alcohol Consumption & $73 / 312(23.4 \%)$ & 98/658 (14.9\%) & $0.99(0.99 ; 1.003)$ & 0.18 & $0.992(0.997 ; 1.007)$ & 0.28 \\
\hline Bathing & $120 / 312(38.5 \%)$ & $197 / 658(29.9 \%)$ & $1.45(1.09 ; 1.93)$ & 0.01 & $1.441(1.057 ; 1.884)$ & $0.02^{a}$ \\
\hline Crossing the river & $102 / 312(32.7 \%)$ & $148 / 658(22.5 \%)$ & $1.58(1.18 ; 2.11)$ & 0.002 & $1.504(1.118 ; 2.022)$ & $0.007^{a}$ \\
\hline Collecting Water & $102 / 312(32.7 \%)$ & $148 / 658(22.5 \%)$ & $1.676(1.214 ; 2.263)$ & 0.001 & $1.683(1.242 ; 2.281)$ & $0.001^{a}$ \\
\hline Doing Laundry & $152 / 312(48.7 \%)$ & $228 / 658(34.7 \%)$ & $1.801(1.366 ; 2.374)$ & $<0.0001$ & $1.738(1.313 ; 2.299)$ & $<0.0001^{a}$ \\
\hline Washing Blankets & $106 / 312(34 \%)$ & $143 / 658(21.7 \%)$ & $1.853(1.373 ; 2.501)$ & $<0.0001$ & $1.815(1.340 ; 2.459)$ & $<0.0001^{a}$ \\
\hline Swimming & $98 / 312(31.4 \%)$ & $128 / 658(19.5 \%)$ & $1.914(1.405 ; 2.607)$ & $<0.0001$ & $1.875(1.373 ; 2.562)$ & $<0.0001^{a}$ \\
\hline Playing & $134 / 312(43.2 \%)$ & $172 / 658(26.1 \%)$ & $2.126(1.598 ; 2.827)$ & $<0.0001$ & $2.042(1.528 ; 2.730)$ & $<0.0001^{a}$ \\
\hline
\end{tabular}

Covariate variables included age, source of drinking water, mother present, father present and caregiver monitoring on weekends

$\mathrm{df}=$ degrees of freedom; sig.=significance level; OR=Exponential coefficient

95\% Cl: Confidence interval $(95 \%)$

a Significant Predictors $(p \leq 0.05)$

Table 3: Predictors of schistosomiasis infection among children. 
Citation: Munsami A, Mitchell C, Lachenicht L, Kvalsvig JD, Kjetland EF, et al. (2016) The Role of Socio-Cultural-Cognition in Disease Prevalence and Risky Behaviour among Children: A Conceptual Framework. J AIDS Clin Res 7: 631. doi: 10.4172/2155-6113.1000631

Page 6 of 7

for further exploration of a socio-cultural-cognitive understanding of intergenerational representations of risks associated with infectious disease. Caregiver monitoring in a South African context may be regarded as a risk factor that is overlooked, as caregivers in this context enforce historically and culturally normative behaviours during monitoring. These social interactions may increase the chances of schistosomiasis infection among young women and young girls living in rural areas, and require strategies that highlight these risks. In line with the global goal to eliminate schistosomiasis among children in developing counties to reduce morbidity and early mortality, it becomes imperative to incorporate social, cultural and cognitively rooted influences on health risk behaviours in treatment and prevention strategies.

\section{Acknowledgement}

The research leading to these results received funding from the European Research Council under the European Union's Seventh Framework Programme (FP7/2007-2013) /ERC Grant agreement no. PIRSES-GA-2010-269245 and The Norwegian Centre for Imported and Tropical Diseases, Oslo University Hospital, Norway.

A special thanks to the girls, parents, teachers and school-staff that made this work possible. We thank all of the research assistants, the manager and the nurses at BRIGHT Research for their contribution. We are grateful for the support from and Prof. B Myrvang at the Norwegian Centre for Imported and Tropical Diseases. We would also like to thank Prof. A Meyer-Weitz and Prof. I Petersen from School of Psychology, UKZN for help with the psychometric scales. We thank clinical social workers and family therapists G Ottesen and U Fauske, Family Therapy Unit Ullevaal, Child and Adolescent Psychiatric Clinic, Oslo University Hospital, Norway for advice. We are thankful for much good advice and data assistance from RF Manyaira and Dr. SD Holmen. We thank Prof. BJ Vennervald, Prof. L van Lieshout and Ms. P. Pillay for scientific advice, Ingrid EA Hegertun and Kristin MS Gundersen are thanked for making, testing and adapting the questionnaire for local conditions. I also thank K-RITH Connect Africa Scholarship.

\section{References}

1. WHO (2015) Guideline on when to start antiretroviral therapy and on preexposure prophylaxis for HIV.

2. Hotez PJ, Brindley PJ, Bethony JM, King CH, Pearce EJ, et al. (2008) Helminth infections: The great neglected tropical diseases. J Clin Invest 118: 1311-1321.

3. Dunn FL (1979) Behavioural aspects of the control of parasitic diseases. Bull World Health Organ 57: 499-512.

4. Kvalsvig JD (1981) The effects of schistosomiasis on spontaneous play activity in black schoolchildren in the endemic areas. An ethological study. S Afr Med J 60: 61-64.

5. King CH (2010) Parasites and poverty: The case of schistosomiasis. Acta Trop 113: 95-104.

6. DiClemente RJ, Hansen WB, Ponton LE (2013) Handbook of adolescent health risk behaviour. Springer Science \& Business Media.

7. Jessor R (1991) Risk behavior in adolescence: A psychosocial framework for understanding and action. J Adolesc Health 12: 597-605.

8. de Graaf H, Vanwesenbeeck I, Woertman L, Meeus W (2011) Parenting and adolescents' sexual development in western societies: A literature review. European Psychologist 16: 21.

9. Kjetland, Kurewa EN, Ndhlovu PD, Midzi N, Gwanzura L, et al. (2008) Female genital schistosomiasis-a differential diagnosis to sexually transmitted disease: genital itch and vaginal discharge as indicators of genital Schistosoma haematobium morbidity in a cross-sectional study in endemic rural Zimbabwe. Tropical Medicine \& International Health 13: 1509-1517.

10. Kjetland EF, Ndhlovu PD, Gomo E, Mduluza T, Midzi N, et al. (2006) Association between genital schistosomiasis and HIV in rural Zimbabwean women. AIDS 20: $593-600$.

11. Kjetland EF, Leutscher PD, Ndhlovu PD (2012) A review of female genital schistosomiasis. Trends Parasitol 28: 58-65.

12. Brodish PH, Singh K (2016) Association between Schistosoma haematobium exposure and human immunodeficiency virus infection among females in
Mozambique. The American Journal of Tropical Medicine and Hygiene 94 1040-1044.

13. Kjetland EF, Hegertun IE, Baay MF, Onsrud M, Ndhlovu PD, et al. (2014) Genital schistosomiasis and its unacknowledged role on HIV transmission in the STD intervention studies. International Journal of STD \& AIDS 25: 705-715.

14. Secor WE (2012) The effects of schistosomiasis on HIVIAIDS infection, progression and transmission. Curr Opin HIV AIDS 7: 254-259.

15. Bruun B, Aagaard-Hansen J (2008) The social context of schistosomiasis and its control: An introduction and annotated bibliography. World Health Organization, Geneva.

16. Lochner K, Kawachi I, Kennedy BP (1999) Social capital: A guide to its measurement. Health Place 5: 259-270.

17. Kawachi I, Kim D, Coutts A, Subramanian SV (2004) Commentary: Reconciling the three accounts of social capital. Int J Epidemiol 33: 682-690.

18. Mazabow M, Burke A, Stuart A (2004) Neuro-epistemology: A post-modernist analysis of the neuro-sciences: research. Health SA Gesondheid 9: 54-66.

19. Oyserman D, Sorensen N, Reber R, Chen SX (2009) Connecting and separating mind-sets: Culture as situated cognition. J Pers Soc Psychol 97: 217-235.

20. Modena CM, Schall VT (2006) Intergenerational representations of schistosomiasis in endemic area, Jaboticatubas, Minas Gerais. Mem Inst Oswaldo Cruz 101: 103-106.

21. Ordóñez CE, Marconi VC (2012) Understanding HIV risk behavior from a sociocultural perspective. J AIDS Clin Res 3.

22. Kleppa E, Ramsuran V, Zulu S, Karlsen GH, Bere A, et al. (2014) Effect of female genital schistosomiasis and anti-schistosomal treatment on monocytes CD4+ T-cells and CCR5 expression in the female genital tract. PLoS One 9: e98593.

23. Magaisa K, Taylor M, Kjetland EF, Naidoo PJ (2015) A review of the contro of schistosomiasis in South Africa. South African Journal of Science 111: 1-6.

24. Hegertun IE, Sulheim Gundersen KM, Kleppa E, Zulu SG, Gundersen SG, et al. (2013) S. haematobium as a common cause of genital morbidity in girls: A cross-sectional study of children in South Africa. PLoS neglected tropical diseases 7: e2104.

25. Nelson KE, Williams CM (2014) Infectious disease epidemiology. Jones \& Bartlett Publishers.

26. Veith I (1993) Hysteria: The history of a disease. Jason Aronson Northvale London.

27. KZN (2015) Annual progress report 2014/2015.

28. Thomassen Morgas DE, Kvalsvig JD, Gundersen SG, Taylor M, Kjetland EF (2010) Schistosomiasis and water-related practices in school girls in rural KwaZulu-Natal, South Africa: Original research. Southern African Journal of Epidemiology and Infection 25: 30-33.

29. Brisson DS, Usher CL (2005) Bonding social capital in low-income neighborhoods. Family Relations 54: 644-653.

30. Tomas JM, Oliver A (1999) Rosenberg's self-esteem scale: Two factors or method effects. Structural Equation Modeling: A Multidisciplinary Journal 6 : 84-98.

31. Bandura A (2006) Guide for constructing self-efficacy scales. Self-efficacy beliefs of adolescents. 5: 307-337.

32. Williams JE, Coombs WT (1996) An analysis of the reliability and validity of bandura's multidimensional scales of perceived self-efficacy. The Annual Meeting of the American Educational Research Association New York.

33. Everitt BS (1980) Contingency tables. Encyclopedia of Statistics in Behaviora Science.

34. Cottrell L, Li X, Harris C, D'Alessandri D, Atkins M, et al. (2003) Parent and adolescent perceptions of parental monitoring and adolescent risk involvement. Parenting: Science and Practice 3: 179-195

35. Fergus S, Zimmerman MA (2005) Adolescent resilience: A framework for understanding healthy development in the face of risk. Annu Rev Public Health 26: 399-419.

36. Brendgen M, Vitaro F, Tremblay RE, Lavoie F (2001) Reactive and proactive 
Citation: Munsami A, Mitchell C, Lachenicht L, Kvalsvig JD, Kjetland EF, et al. (2016) The Role of Socio-Cultural-Cognition in Disease Prevalence and Risky Behaviour among Children: A Conceptual Framework. J AIDS Clin Res 7: 631. doi: 10.4172/2155-6113.1000631

Page 7 of 7

aggression: Predictions to physical violence in different contexts and moderating effects of parental monitoring and caregiving behavior. Journal of Abnormal Child Psychology 29: 293-304

37. Dick DM, Viken R, Purcell S, Kaprio J, Pulkkinen L, et al. (2007) Parental monitoring moderates the importance of genetic and environmental influences on adolescent smoking. J Abnorm Psychol 116: 213-218.
38. Laird RD, Pettit GS, Bates JE, Dodge KA (2003) Parent's monitoring-relevant knowledge and adolescents delinquent behavior: Evidence of correlated developmental changes and reciprocal influences. Child development 74: 752-768.

39. Dellar RC, Dlamini S, Karim QA (2015) Adolescent girls and young women: Key populations for HIV epidemic control. J Int AIDS Soc 18: 19408. 